\title{
What's so good about the Kings Fund management course?
}

\author{
M.F. Bristow and A. Douzenis
}

In an era where management training is vital for any would-be consultant, the Kings Fund training course for senior registrars is the best known and most expensive. Examining it critically, we foel that despite ths haws it is still worth the extra money both for tis wealth of practical exercises and for the unique, although not very reassuring, glimpse it affords us of management ideology at source. Local courses, although unable to reproduce the atmosphere, could benefit from its practical emphasis.

It is accepted wisdom among SRs applying for consultant posts that a management course on one's CV is de rigeur and the word on the street is that the best one of all is the Kings Fund course. It certainly has a long waiting list; with a course running every three months it is still necessary to book three months in advance. But with a course fee of $£ 700$ and rising the potential consumer may need six months to drum up the cash. The 20 or so SRs from diverse medical specialties (curiously none from community medicine) who turned up at the Kings Fund College on the first morning had various aims in mind, some concrete such as learning to hold their own with managers, some more nebulous such as understanding the current health service reforms. As SRs who had been on other management courses and emerged unsatisfied, the authors, two of only three psychiatrists on the course, came to see if the Kings Fund could reach parts that other courses had not reached.

The needs of psychiatrists on management courses have been discussed before, most comprehensively by Jadresic (1992) who pointed out the drawbacks of presenting management theory without any critical discussion. Psychiatrists, possibly more than other specialists, are used to dealing critically with theories and given that much of management theory derives from social psychology her point is valid. Part of the problem, as we have noticed on previous courses, comes from the heterogenous nature of the syllabus. There is the purely factual (principles of accounting) combined with the almost-factual (history of the NHS) and the highly speculative (various theories of management and team functioning). If all are presented together in an uncritical way the credibility of the latter is weakened. But there are other, more implicit, requirements from management courses; namely to get a feel for the way managers operate in real life and to appreciate what, if anything, lies behind all these theories and structures.

The Kings Fund College is a substantial redbrick pile that overlooks Kensington Palace and evokes comparisons with a university college with panelled walls, long dining tables and a subsidised bar. This gave the course a sense of identity absent from the majority of extramural courses, taking place as they do in borrowed and anonymous classrooms. The accommodation, in a nearby hotel, was superior to the usual spartan college-style facilities. The course organisers evidently believe that if the delegates are well looked after, they will achieve superior results. This axiom, despite the influential role the Kings Fund has had in the health service over recent years, does not seem to have impinged on the consciousness of those who manage at the NHS coalface.

The course lasted a week. Its composition changes every time, being shaped by the comments of the previous intake, but can be broadly divided into three spheres, didactic teaching, role play or exercise, and self-exposition. The selfexposition, or in management patols personal growth techniques, was tame by group analytic standards but one surgical colleague evidently found it too hot for he declined to participate in an exercise involving a pictorial representation of hopes and achievements. The didactic teaching was hampered by the problems with the syllabus already mentioned but was at least comprehensive, leaving most of us satisfied about such management mysteries as business plans, capital charges and robust intermediate structures (hospital trusts).

Most useful of all, interwoven with the didactic sessions were the role-plays and exercises which enabled us to think ourselves into the position of managers. The exercises varied from simple scripted tasks to be worked out in groups to a full-scale 'commando raid' (yes, there was a 
preponderance of males on the course) during which we descended on real-life local units, interviewed various managers and fed back our findings to other members. Although most course members initially expressed a vague distrust of role-plays, they were challenging and at times uncomfortable enough to serve a serious purpose.

If the course scored a plus on the practical side, as regards the ideology of management, our other requirement, it was less reassuring. There was an uncritical mixing of the definite with the arbitrary which led to certain dubious ideological goods being passed on along with the facts and axioms. The fixity of health service expenditure and the innovation of the means to achieve it, acts of pure ideological whim, sat uneasily among dry definitions of management structures. Even stranger was the juxtaposition of a management model of change, bristling with initial objectives, flow charts and feedback loops with the admission that there is no overall supervision or guidance of the current health service changes.

The most revealing illustration of the academic management viewpoint came during an exercise late one afternoon. We had been given a script which illustrated the poor communication between and within the various agencies concerned with a fictitious old lady whose last days had been less than perfect. Collectively biting back the urge to say that her death had not been particularly bad and we had known far worse go unpunished, not to say unnoticed, we broke into groups and set about role-playing the various agencies trying to ensure that the same thing did not happen again. When it came to 5 p.m. the group role-playing social services who comprised those most sceptical about the old lady's injustice decided, perhaps in homage to their real-life namesakes, to shut up shop and go home. For this they were berated soundly by the organisers who intimated that if they could not see what was iniquitous about her death then they were not fit to be . . . etc. What struck us as strange were not the organisers' utopian goals but their lack of appreciation of the pragmatism exercised by those who deliver real-life services.

It is a fair bet that management courses will continue to proliferate and the trainee will have to weigh the merits of expensive independents such as the Kings Fund against a cheaper local version. The Kings Fund is more impressive than any we have seen but it is not impossible for local course organisers to learn from it, especially with regard to its strong emphasis on practical exercises which made the course a pleasant and memorable experience. Psychiatrists may regard the presence of other specialists as a drawback but until organisers of courses for psychiatrists allow for our greater sophistication towards vague and conflicting models it is reassuring to see physicians and surgeons in the same boat as ourselves. The opulent presentation and the academic atmosphere of the Kings Fund are probably unreproducible and it is certainly a course for those who think they might want to become managers.

Of course, trainees of the future might not get the choice, being simply co-opted onto in-house courses where the line between education and appraisal becomes increasingly thin. In such a brave new world the Kings Fund course will be remembered as an enjoyable way of finding out about management without feeling it is trying to find you out.

\section{Reference}

JADRESIC, D. (1992) Management training - what do we need? Psychiatric Bulletin. 16, 86-87.

*M. F. Bristow, Lecturer and Honorary Senior Registrar: and A. Douzenis, Senior Registrar, Department of Psychiatry. Charing Cross Hospital, Fulham Palace Road, London W6

*Correspondence 